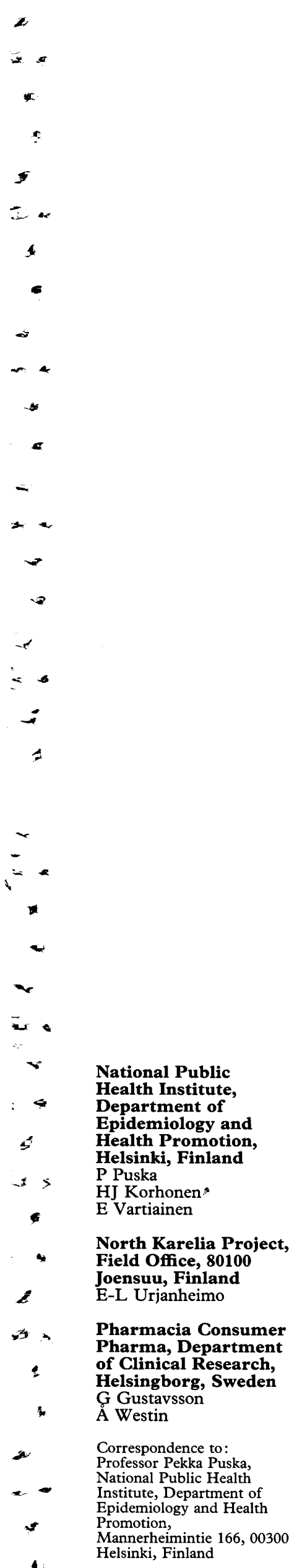

\title{
Combined use of nicotine patch and gum compared with gum alone in smoking cessation: a clinical trial in North Karelia
}

\author{
Pekka Puska, Heikki J Korhonen, Erkki Vartiainen, Eeva-Liisa Urjanheimo, \\ Gunnar Gustavsson, Ake Westin
}

\begin{abstract}
Objectives - To study the safety and efficacy of combined use of nicotine patch and nicotine gum in smoking cessation $v$ gum only.

Design - A randomised double blind trial with 12 month follow up. Both groups were asked to use the patch $(16 \mathrm{~h}$ nicotine or placebo) for 18 weeks and at least four pieces of $2 \mathrm{mg}$ nicotine gum per day (active patch/active gum = "combination" group; placebo patch/active gum = "gum only" group).

Setting - 10 health centres in the province of North Karelia, Finland, with trained public health nurses giving the study medication plus simple smoking cessation advice during scheduled study visits.
\end{abstract}

Subjects -300 voluntary adult smokers recruited from their respective communities using mainly newspaperadvertisements.

Main outcome measures - Self reported smoking status, verified by expired air carbon monoxide, with abstinence defined as complete sustained abstinence after the first week.

Results - The abstinence rates in the combination $v$ gum only groups were $39 \% v$ $28 \%$ at three months $(p=0.038)$ and $24 \%$ $v 17 \%$ at 12 months $(p=0.154)$.

Conclusions - Combined use of nicotine patch and gum improves at least short term smoking cessation rates compared with gum alone, and can useful for individualised smoking cessation.

(Tobacco Control 1995; 4: 231-235)

Keywords: smoking cessation; nicotine replacement

\section{Introduction}

Smoking cessation is a major challenge for public health. The harmful consequences of smoking to populations and individuals have led to a search for effective methods to help smokers get rid of this addiction. In Finland, as in many other countries, the majority of smokers are concerned about their smoking and would like to stop. ${ }^{1}$

Nicotine replacement therapy has for several years been used as an aid in smoking cessation.
Nicotine gum has been on the market for nearly 20 years. The efficacy of nicotine gum has been shown convincingly in many studies, recently reviewed in three meta-analyses. ${ }^{2-4}$

During the last few years, nicotine replacement therapy has also been available in the form of skin patches. The efficacy of patches has been shown in several studies, although less experience is available than for the gum. ${ }^{3-5}$ The meta-analyses of Silagy $e t a l^{3}$ included 39 gum trials and nine patch trials. According to this analysis the overall effect (odds ratio) of gum was 1.61 and that of the patch was 2.07 (compared with placebo).

The gum and the patch have distinctly different methods of action. The patch gives a relatively stable concentration of nicotine in blood, while the gum leads to increased blood nicotine concentrations after use of each piece of gum.

Both the patches and gum have advantages and disadvantages. The advantages of the patch are its easy use, its invisibility, and the steady availability of nicotine in the blood. A disadvantage is that it does not allow the user to respond to the urge to smoke in the same way as smoking. The side effects of the patch are usually mild, in most cases minor skin problems. $^{6}$

The advantage of the gum is that the smoker can respond to the urge to smoke by taking pieces of gum (although the blood peaks do not follow as rapidly as after smoking). A disadvantage of the gum for many people is the visibility of its use. Also, long term use of many daily pieces may cause mandibular joint or other oral problems.

Because of the different advantages and disadvantages of the two methods, an obvious question is whether the combined use of patch and gum confer some advantages over the the single use of either product. Combined use could help to increase the blood nicotine level closer to that associated with smoking, while possible side effects of doing that with a single form of administration might be reduced. Also one could postulate that the patch could give some permanent protection, while the additional use of gum could provide a means for coping with the urge to smoke.

Combined treatment seems to reduce withdrawal symptoms more than either treatment alone ${ }^{7}$ and the patch and gum combination has 
been suggested for use with highly dependent smokers. ${ }^{8}$

In connection with the North Karelia Project, a major national community based prevention programme in Finland, the efficacy of nicotine gum was tested in the mid-1970s. ${ }^{9}$ After positive results and experience, the use of gum has been encouraged in the programme. The 20 year results of the project show a remarkable decline in smoking among males in North Karelia, from $52 \%$ to $32 \% .^{1011}$

After nicotine skin patches became available, the North Karelia Project became interested in their efficacy. Because of the above considerations the decision was made to carry out a well designed trial on the usefulness of combining the patch with gum compared with the use of gum alone, the previously tested method.

\section{Methods}

The trial was carried out in North Karelia, Finland, from spring 1992 to autumn 1993. Altogether 300 smokers were recruited as volunteers, using mainly newspaper advertisements. More than 1000 smokers volunteered to participate in the study. In Finland, American-style filtered cigarettes are the main cigarette type smoked.

The trial was carried out at 10 centres in the province of North Karelia. Of these, six were public health centres, two were occupational health stations, and one was a private health clinic. The North Karelia Project office acted as coordinating centre and also was one centre of the trial. At the centres the trial was conducted by public health nurses who were carefully instructed about the tasks of the trial before its start. Their performance was closely monitored by the project office throughout the study.

The inclusion criteria for the trial were: age between 20 and 65 years, smoking at least 10 cigarettes a day, having smoked three years or more, and personally willing to stop smoking and to comply with the requirements of the protocol. The exclusion criteria were: recent myocardial infarction, pregnancy or breast feeding, regular psychotropic medication, use of smokeless tobacco, generalised dermatological disorder, active peptic ulcer, active temporomandibular joint disease, and currently following any form of smoking cessation programme.

All subjects were informed about the general purpose, design, and conduct of the study, and they gave their written consent. The study was approved by the ethical issues committee of the National Public Health Institute, Helsinki.

The subjects were randomly allocated to one of two groups: active patch and active gum ("combination"), and placebo patch and active gum ("gum only"). The study was carried out in a strictly double blind fashion.

In the combination group all subjects were instructed to use one $15 \mathrm{mg}$ patch $(16 \mathrm{~h}$ administration, Nicorette) daily for 12 weeks. After that, one patch of $10 \mathrm{mg}$ was used daily for three weeks, and one patch of $5 \mathrm{mg}$ for an additional three weeks (patch tapering). The gum only group received identical placebo patches.

Nicotine gum (2 mg Nicorette specially labelled for use in clinical research) was given for ad libitum use, but the subjects were encouraged to use at least four pieces a day. The use of the gum was allowed throughout the 12 month study period, but its withdrawal was encouraged after six months.

In addition to the study medication, general smoking cessation advice was given by the study's public health nurses. The intervention involved conventional instructions on study medication use and on behavioural aspects of smoking cessation within relatively short time periods and feasible in general primary health care settings, but did not include formal psychotherapy.

The subjects paid visits to their clinic at entry and at weeks 1, 3, 6, 12, 26, and 52. At entry smoking status, smoking history, and social and behavioural background were recorded, as well as medical history and the Fagerström tolerance questionnaire (FTQ) ${ }^{12}$

Smoking status was recorded at each visit, as well as weight and expired air carbon monoxide using a $\mathrm{CO}$ analyser (Bedfont). Subjects kept a diary card on their daily use of gum. Saliva cotinine was measured at entry, and after three weeks and 26 weeks. The laboratory analyses were done retrospectively after completion of the study from frozen samples using an automated polarisation fluoroimmunoassay. ${ }^{13}$

For safety assessment the subjects were asked at each visit about possible adverse events. The assessment was based on an open ended, non-leading question. Adverse events that had occurred or deteriorated since the previous visit were recorded, and their severity and duration were assessed.

Success was defined as continuously lapsefree abstinence after week 1 verified with a $C O$ level in expired air of less than $10 \mathrm{ppm}$ at all visits after week 1.

Subjects who were smoking at week 3 or later or who did not return to the clinic in spite of requests were regarded as failures. Subjects with severe adverse events or subjects who rejected further treatment were withdrawn from treatment, but remained in the study.

\section{STATISTICAL METHODS}

Statistical tests used are two tailed and at a $p=0.05$ significance level. No formal adjustments for multiplicity have been made, but exact $p$ values are presented. Baseline variables have been checked for homogeneity between treatment groups. All subjects were included in the assessment of outcome.

The Student $t$ test was used for all quantitative variables (for example, number of gum pieces used). Discrete data with two or more categories have been analysed using models for logistic regression, Pearson's $\chi^{2}$ test, or the Mann-Whitney U test. For "Time to relapse" the log rank test was used.

A separate analysis of efficacy was performed using logistic regression with 19 variables as 
Table 1 Background information on the two groups

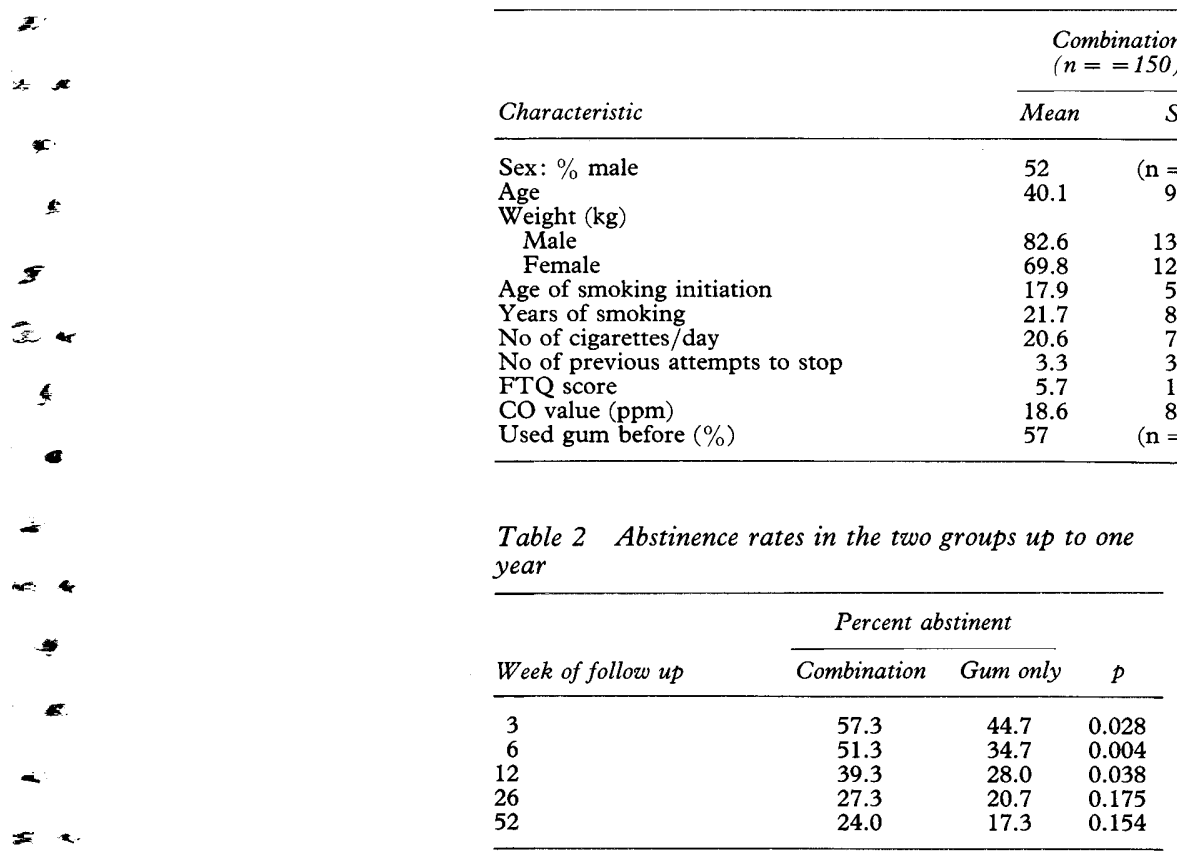

independent factors (age, treatment, $\mathrm{CO}$ at baseline, weight, eight FTQ questions, and seven questions on smoking history and previous cessation attempts) and smoking status at one year as the dependent variable.

\section{Results}

Table 1 shows the background features of the subjects in the two groups. The comparability of the groups was good, with no significant differences in any baseline characteristics.

The abstinence rates at different follow up times are given in table 2 and in the figure. The results show significant differences in favour of the combination up to 12 weeks and a significant difference between the two curves $(p=$ $0.04, \log$ rank test).
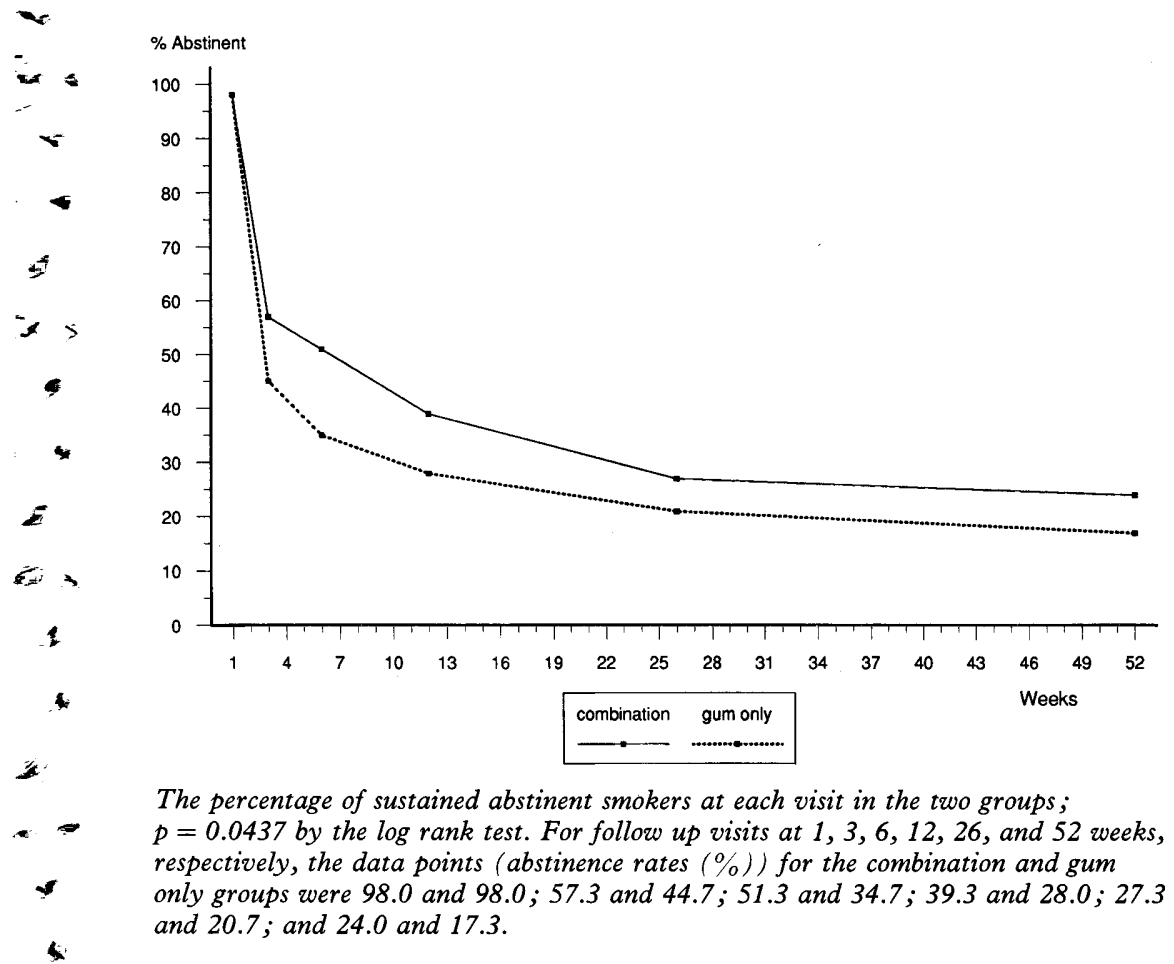

The percentage of sustained abstinent smokers at each visit in the two groups; $p=0.0437$ by the log rank test. For follow up visits at 1, 3, 6, 12, 26, and 52 weeks, respectively, the data points (abstinence rates $(\%)$ ) for the combination and gum only groups were 98.0 and $98.0 ; 57.3$ and $44.7 ; 51.3$ and $34.7 ; 39.3$ and $28.0 ; 27.3$ and 20.7 ; and 24.0 and 17.3 .
A multivariate analysis was performed using logistic regression with known or possible prognostic factors as independent variables and smoking status at 1 year as the dependent variable. Only the answer to the question "Which cigarette do you most of all hate to give up?" had a significant impact (odds ratio $=1.89,95 \%$ confidence interval $=1.08-3.32$ ). The risk of relapse was higher for subjects who most of all hated to give up the first cigarette in the morning.

Since both of the groups used nicotine chewing gum, a question about previous experience of the gum was combined with treatment given and a survival analysis was performed for the four groups. The success rate was highest for the group with active patch and no previous experience of gum, and lowest for the group with placebo patch and previous experience of gum. No curves crossed each other. Results of the log rank test showed, however, no significant differences between strata.

At the 12 week follow up $70 \%$ of the combination group (active patch) and $58 \%$ of the gum only group (placebo patch) used the patch $(p=0.04)$. During the three months both groups used on average four pieces of gum a day, thereafter reducing use. Gum use was initially slightly higher in the gum only group (table 3 ).

Table 4 gives the results of the saliva cotinine analyses. They indicate higher cotinine levels in the combination group during active patch use.

There was an increase in body weight during the study in both groups. This increase was among those who attended visits from weeks 3 to 12 , and was significantly smaller in the combination group compared with the gum alone group. The respective increases (in $\mathrm{kg}$ ) in the two groups from baseline were 0.1 and 1.2 ( 3 weeks), 1.0 and 2.5 (12 weeks), 1.1 and 3.3 ( 26 weeks), and 2.7 and 4.0 ( 52 weeks). Among those totally abstinent the increases were somewhat greater, and the differences between the group were again significant at 3 and 12 weeks of follow up: 0.6 and 1.2 ( 3 weeks), and 2.2 and 3.2 (12 weeks).

The reported adverse effects were relatively few. Any type of itching at any follow up was reported by $29 \%$ of the combination group and $11 \%$ of the gum only group $(\mathrm{p} \ll 0.001)$. These were moderate or severe at any point of follow up in $9 \%$ and $5 \%$ of subjects re- 
Table 3 Compliance with the patch and average number of gum pieces per day among users (and percentage of users) at the different follow up times

\begin{tabular}{|c|c|c|c|c|c|c|c|c|}
\hline \multirow{2}{*}{$\begin{array}{l}\text { Follow } \\
\text { up } \\
\text { weeks }\end{array}$} & \multicolumn{3}{|c|}{$\begin{array}{c}\text { Mean No of gum pieces } \\
\text { (\% of users) }\end{array}$} & \multicolumn{3}{|c|}{ Use of patch $(\%)$} & \multicolumn{2}{|c|}{$\begin{array}{l}\text { Number of subjects } \\
\text { at follow up }\end{array}$} \\
\hline & Combination & Gum only & $p$ & Combination & Gum only & $p$ & Combination & Gum only \\
\hline $\begin{array}{l}1 \\
12 \\
26 \\
52\end{array}$ & $\begin{array}{l}3.9(100) \\
3.8(95) \\
2.1(90) \\
0.6(69)\end{array}$ & $\begin{array}{l}4.7(99) \\
4.3(97) \\
2.4(93) \\
0.9(74)\end{array}$ & $\begin{array}{l}0.03 \\
0.28 \\
0.42 \\
0.03\end{array}$ & $\begin{array}{l}87 \\
70 \\
- \\
-\end{array}$ & $\begin{array}{c}86 \\
58 \\
- \\
-\end{array}$ & $\begin{array}{l}0.86 \\
0.04\end{array}$ & $\begin{array}{l}148 \\
130 \\
115 \\
105\end{array}$ & $\begin{array}{r}148 \\
118 \\
107 \\
92\end{array}$ \\
\hline
\end{tabular}

Table 4 Saliva cotinine levels $(\mathrm{ng} / \mathrm{ml})$ in subjects abstinent after 26 weeks (slips allowed) and in all subjects evaluated at the follow up

\begin{tabular}{lrrrrrr}
\hline & \multicolumn{2}{c}{ Combination } & \multicolumn{2}{c}{ Gum only } \\
\cline { 2 - 3 } & Mean & $n$ & & Mean & $n$ & $p$ \\
\hline Abstinent subjects & & & & & \\
$\quad$ week 0 & 338 & 51 & 332 & 38 & 0.868 \\
$\quad$ week 3 & 198 & 52 & 92 & 40 & 0.000 \\
$\quad$ week 26 & 31 & 50 & 51 & 36 & 0.179 \\
All subjects & & & & & \\
$\quad$ week 0 & 351 & 145 & 351 & 140 & 0.988 \\
$\quad$ week 3 & 228 & 138 & 160 & 137 & 0.000 \\
$\quad$ week 26 & 147 & 105 & 198 & 88 & 0.035 \\
\hline
\end{tabular}

Table 5 Moderate or severe possible adverse effects reported at any follow up

\begin{tabular}{lcc}
\hline & $\begin{array}{c}\text { Moderate or severe at any } \\
\text { follow up }(\%)\end{array}$ \\
\cline { 2 - 3 } Adverse effect & Combination & Gum only \\
\hline Itching & 9 & 5 \\
Rash & 3 & 4 \\
Perspiration & 2 & 3 \\
Headache & 2 & 5 \\
Malaise & 1 & 3 \\
Dyspepsia & 1 & 5 \\
Paraesthesiae & 1 & 3 \\
Pharyngitis & - & 3 \\
\hline
\end{tabular}

No significant differences between the groups

spectively (NS). Otherwise the rate of adverse effects was low and no significant differences were observed between the two groups (table 5).

\section{Discussion}

The results show that the initial cessation rates were significantly higher at up to 3 months in the combination group than in the group with gum as the only form of nicotine replacement treatment. The trend continued during the one year follow up period.

The results suggest that combination therapy is a useful alternative in smoking cessation. However, several reservations should be kept in mind. One might ask whether some improvement could have been achieved simply by increasing the dose of nicotine in single therapy. Improved results with single therapy could possibly also be achieved with longer treatment in all subjects or with some other improvement in the case of single therapy.

Because the greatest difference in abstinence rates between the groups was at six weeks after cessation, the primary effect of the combination treatment may be suppression of early withdrawal symptoms. Also the difference in early weight gain supports this, although combination treatment may also prevent relapse and thus prevent the abstinence curves from converging.

The overall cessation rates match previous experience. Considering that the overall intervention was relatively simple, the method used is certainly feasible for public health use in a primary health care setting.

The study was carried out in North Karelia where considerable activity had taken place during the previous 20 years to reduce smoking rates in the population. Thus one could expect that present smokers might be more resistant to smoking cessation. Indeed, the subjects in this study had made several previous attempts to quit, and previous use of nicotine gum was quite common.

On the other hand, subjects of this study were mainly rather moderate smokers (mean $\mathrm{CO}$ less than $20 \mathrm{ppm}$ ). The efficacy of combination therapy may be greater among heavier smokers. Gum use was relatively low, and higher gum use might have changed the results.

For reasons of study economics, only a two group design could be used: comparison of combination therapy with gum alone, a previously available and tested method. ${ }^{5}$

The results of the present study are corroborated by those of a similar study by Kornitzer et al. ${ }^{14}$ In that Belgian study the combination of patch and gum was compared with patch alone in an otherwise similar study design. In that study initial abstinence rates were also significantly higher in the combination group and the trend continued during the follow up period. Bittoun and Petrie ${ }^{15}$ have reported favourable results from Australia with the combined use of gum and patch in an open clinical cessation study. Also, as noted above, Fagerström et al found the combination superior to patch or gum alone in treating withdrawal symptoms in a short term double blind study. ${ }^{7}$

Smoking addiction is generally hard to break. As we strive for more effective cessation methods, we should be content with the partial success we have achieved - as is clearly shown in nicotine replacement therapy studies. Compared with the differences in efficacy between active nicotine replacement therapy and placebo, any differences in efficacy between different kinds of active replacement are likely to be small. However, if such differences can be found, as in this study during the first three months, they may help us to better choose the right therapy.

A well known limitation of this kind of rigorous double blind trial is that we cannot 
have the advantages of more individualised treatments, as in the case of clinical practice. The results of this study indicate that combined use of nicotine patch and gum may be useful in individualised smoking cessation, perhaps especially among moderately and highly nicotine dependent smokers who need both permanent nicotine replacement and responses to cravings at certain times. Obviously combination therapy should be accompanied by appropriate behavioural counselling.

1 Berg M-A, Helakorpi S, Puska P. Suomalaisen aikuisväestön terveyskäyttäytyminen kevät 1993. Health Behaviour among Finnish Adult Population Spring 1993. Kansanterveyslaitoksen julkaisuja. Publications of the National Public Health Institute. B 10/1993. Helsinki 1993.

Foulds J. Does nicotine replacement therapy work? $A d$ diction $1993 ; 88$ : 1473-8.

3 Silagy C, Mant D, Fowler G, Lodge M. Meta-analysis on efficacy of nicotine replacement therapies in smoking efficacy of nicotine replacement the

4 Tang JL, Law $M$, Wald $N$. How effective is nicotine replacement therapy in helping people to stop smoking? $B M \mathcal{F} 1994 ; 308$ : $21-6$.

$5 \mathrm{Li}$ Wan Po A. Transdermal nicotine in smoking cessation: a meta-analysis. Eur f Clin Pharmacol 1993; 45: 519-28.
6 Fiore MC, Jorenby DE, Baker TB, Kenford SL. Tobacco dependence and the nicotine patch. $¥ A M A 1992 ; 268$ : depende.

7 Fagerström KO, Schneider NG, Lunell E. Effectiveness of nicotine patch and nicotine gum as individual versus combined treatments for tobacco withdrawal symptoms. Psychopharmacology 1993; 111: 271-7.

8 Hughes, JR. An algorithm for smoking cessation. Arch Fam Med $1994 ; 3: 280-5$

9 Puska P, Björkvist S, Koskela K. Nicotine containing chewing gum in smoking cessation: a double-blind trial with half year follow-up. Add Behav 1979; 4:141-6.

10 Puska $P$, Vartiainen E, Tuomilehto J, Jousilahti P, Korhonen HJ, Tamminen $M$, et al. Sydän-ja verisuonitautien riskitekijöiden muutokset Suomessa. Suom Lähäril 1993; 48:3017-22

11 Vartiainen E, Puska P, Jousilahti P, Korhonen HJ, Tuomilehto J, Nissinen A. Twenty-year trends in Tuomilehto J, Nissinen A. Twenty-year trends in coronary risk factors in North Karelia and in other

12 Heatherton TF, Kadowski LT, Frecker RC, Fagerström KO. The Fagerström test for nicotine dependence: a revision of the Fagerström tolerance questionnaire. $\mathrm{Br} \mathcal{f}$ Addict 1991 ; 36: 1119-27.

13 Eremin SA. Urinary cotinine fluoroimmunoassay for smoking status screening adapted to an automated analyzer. Analyst $1992 ; 117$ : 697-9.

14 Kornitzer M, Boutsen M, Dramaix M, Thijs J, Gustavsson G. Efficiency and safety of combined use of nicotine patch and nicotine gum in smoking cessation: a placebo and nicotine gum in smoking cessation: a placebo Future Directions in Nicotine Replacement Therapy. Future Directions in Nicotine

15 Bittoun R, Petrie J. Nicotine patch combined with nicotine gum in smoking cessation. The International Congress on Smoking Cessation. SECC, Glasgow, 1994. 